OPEN ACCESS

International Journal of

Environmental Research and

Public Health

ISSN 1660-4601

www.mdpi.com/journal/ijerph

Article

\title{
Investigation of Legionella Contamination in Bath Water Samples by Culture, Amoebic Co-Culture, and Real-Time Quantitative PCR Methods
}

\author{
Akiko Edagawa ${ }^{1,2}$, Akio Kimura ${ }^{3}$, Takako Kawabuchi-Kurata ${ }^{4}$, Shinichi Adachi ${ }^{1}$, \\ Katsunori Furuhata ${ }^{5}$ and Hiroshi Miyamoto ${ }^{2, *}$
}

1 Division of Environment Health, Osaka Prefectural Institute of Public Health, Osaka 537-0025, Japan; E-Mails: edagawa@iph.pref.osaka.jp (A.E.); adachi@iph.pref.osaka.jp (S.A.)

2 Division of Microbiology, Department of Pathology and Microbiology, Faculty of Medicine, Saga University, Saga 849-8501, Japan

3 Division of Planning and Coordination, Osaka Prefectural Institute of Public Health, Osaka 537-0025, Japan; E-Mail: akkimura@iph.pref.osaka.jp

4 Division of Virology, Osaka Prefectural Institute of Public Health, Osaka 537-0025, Japan; E-Mail: kurata@iph.pref.osaka.jp

5 School of Life and Environmental Science, Azabu University, Kanagawa 252-5201, Japan; E-Mail: furuhata@azabu-u.ac.jp

* Author to whom correspondence should be addressed; E-Mail: miyamoth@cc.saga-u.ac.jp; Tel.: +81-952-34-2253; Fax: +81-952-34-2252.

Academic Editors: Nicholas Frederick Gray and Panagiotis Karanis

Received: 1 September 2015 / Accepted: 14 October 2015 / Published: 19 October 2015

\begin{abstract}
We investigated Legionella contamination in bath water samples, collected from 68 bathing facilities in Japan, by culture, culture with amoebic co-culture, real-time quantitative PCR (qPCR), and real-time qPCR with amoebic co-culture. Using the conventional culture method, Legionella pneumophila was detected in 11 samples (11/68, $16.2 \%)$. Contrary to our expectation, the culture method with the amoebic co-culture technique did not increase the detection rate of Legionella (4/68, 5.9\%). In contrast, a combination of the amoebic co-culture technique followed by qPCR successfully increased the detection rate $(57 / 68,83.8 \%)$ compared with real-time qPCR alone $(46 / 68$, $67.6 \%$ ). Using real-time qPCR after culture with amoebic co-culture, more than 10 -fold
\end{abstract}


higher bacterial numbers were observed in 30 samples $(30 / 68,44.1 \%)$ compared with the same samples without co-culture. On the other hand, higher bacterial numbers were not observed after propagation by amoebae in 32 samples $(32 / 68,47.1 \%)$. Legionella was not detected in the remaining six samples $(6 / 68,8.8 \%)$, irrespective of the method. These results suggest that application of the amoebic co-culture technique prior to real-time qPCR may be useful for the sensitive detection of Legionella from bath water samples. Furthermore, a combination of amoebic co-culture and real-time qPCR might be useful to detect viable and virulent Legionella because their ability to invade and multiply within free-living amoebae is considered to correlate with their pathogenicity for humans. This is the first report evaluating the efficacy of the amoebic co-culture technique for detecting Legionella in bath water samples.

Keywords: Legionella; amoebic co-culture; Acanthamoeba; bath water; intracellular growth

\section{Introduction}

Legionella are gram-negative bacteria and the causative agent of legionellosis, a group of related illnesses that include severe pneumonia and non-pneumonic Pontiac fever [1]. Infection by Legionella occurs through the inhalation or aspiration of aerosols generated from contaminated environmental water found in structures such as cooling towers, evaporative condensers of large air-conditioning systems, whirlpool spas, showers, and hot water tanks [1]. Among the Legionella, Legionella pneumophila (L. pneumophila) is the major disease causative agent, although other species such as L. anisa, L. bozemanii, L. dumoffii, L. gormanii, and L. longbeachae are also human pathogens [1]. More than 1100 cases of legionellosis in Japan, caused by contaminated artificial whirlpool spas or natural hot springs, were reported in Infectious Agents Surveillance Report 2014 [2]. In 2002, a major outbreak originating from a newly opened hot spring spa involved 295 patients with seven deaths [3]. Hence, Legionella infection caused by contaminated bath water is an important public health concern in Japan [4-6], and sensitive detection and identification of Legionella from bath water samples is crucial for legionellosis control.

Culture methods are commonly used to detect Legionella in environmental samples, including bath water [7-11]. However, Legionella are transformed into a viable but nonculturable (VBNC) form by certain environmental conditions [12-14]. Recently, quantitative real-time PCR (real-time qPCR) specific for Legionella 16S rRNA, 5S rRNA, or macrophage infectivity potentiator (mip) genes have been widely applied to overcome the limitations of standard culture methods [15-18]. Real-time qPCR is much more sensitive for detecting lower levels of contamination compared with culture methods. Moreover, real-time qPCR can detect nonculturable Legionella such as the VBNC types.

In natural aquatic environments, Legionella are taken up by FLA including Acanthamoeba, Vahlkamphia, and Hartmannella, by phagocytosis [1]. Legionella have the ability to survive and multiply in FLA and are released from FLA into the environment [1]. In addition, Legionella can multiply in FLA and recover their culturability [12,19]. To use this association between Legionella and FLA for the sensitive detection of Legionella, an amoebic co-culture technique was developed to 
isolate L. pneumophila and L. anisa from clinical samples [20,21]. In particular, Schalk et al. (2012) isolated several Legionella, including L. pneumophila belonging to sequence types isolated from legionellosis patients in the Netherlands [22]. These reports suggested that the amoebic co-culture technique was useful for detecting Legionella responsible for human disease in environmental water samples. However, the efficacy of the amoebic co-culture technique for detection of Legionella from bath water samples has not yet been determined.

In this study, we investigated Legionella contamination in bath water samples, collected from 68 bathing facilities in Japan, by culture, culture with amoebic co-culture, real-time quantitative PCR (qPCR), and real-time qPCR with amoebic co-culture.

\section{Materials and Methods}

\subsection{Sample Collection}

Bath water samples were collected from 68 hot spring spas located in Osaka Prefecture, Japan. A total of 68 water samples of $500 \mathrm{~mL}$ each were collected in sterile bottles containing sodium thiosulfate at a final concentration of $0.01 \%$. Sample temperature and free chlorine concentration were measured at the time of sampling. Free chlorine concentration was measured by the diethyl-p-phenylenediamine (DPD) method (DPD test Wako; Wako Pure Chemical Industries Ltd, Osaka, Japan). Water samples were immediately delivered to the laboratory at $4{ }^{\circ} \mathrm{C}$, and microbiological analyses were performed on the day of collection.

\subsection{Sample Processing}

Each bath water sample was concentrated by filtration through a $0.22 \mu \mathrm{m}$ pore-size polycarbonate filter (Advantec Tokyo Co. Ltd., Tokyo, Japan). The membrane was then immersed in $5 \mathrm{~mL}$ of sterile deionized water, vortexed for $1 \mathrm{~min}$, and shaken vigorously 50 times. A $3 \mathrm{~mL}$ aliquot of the suspension was heated in a water bath at $50{ }^{\circ} \mathrm{C}$ for $30 \mathrm{~min}$ and used for culture with or without the amoebic co-culture technique as described below. The remaining $2 \mathrm{~mL}$ of suspension was stored at $-20{ }^{\circ} \mathrm{C}$ for DNA extraction.

\subsection{Isolation and Characterization of Legionella by The Culture Method}

Aliquots $(100 \mu \mathrm{L})$ of the $3 \mathrm{~mL}$ treated samples were inoculated onto Wadowsky-Yee-Okuda agar plates containing $5 \mu \mathrm{g} / \mathrm{mL}$ vancomycin and $100 \mathrm{U} / \mathrm{mL}$ polymyxin with alpha-ketoglutarate (WYO-alpha plates; Eiken Chemical Co. Ltd., Tokyo, Japan). After incubation for 5-7 days at $37{ }^{\circ} \mathrm{C}, 1-50$ colonies showing characteristics of Legionella species were selected and cultured on blood agar plates (Nikken Seibutsu Co. Ltd., Tokyo, Japan) and on buffered charcoal-yeast extract agar plates with alpha-ketoglutarate (BCYE-alpha; Eiken Chemical Co. Ltd.). After three days at $37{ }^{\circ} \mathrm{C}$, iolates that grew on BCYE-alpha but did not grow on blood agar were examined by gram staining. Gram negative staining was considered suggestive of the presence of Legionella species. The colonies were observed under UV light and 1-5 colonies were randomly selected for the latex agglutination test (Kanto Chemical Co., Tokyo, Japan) and the immune serum agglutination test (Denka Seiken Co. Ltd., Tokyo, Japan) to identify the serogroup of L. pneumophila, L. bozemanii, L. dumoffii, L. gormanii, and L. micdadei. 
In addition, DNA-DNA hybridization tests were performed according to the manufacturer's instructions (Kyokuto Pharmaceutical Industrial Co. Ltd., Tokyo, Japan).

\subsection{Amoebic Co-Culture Technique}

Acanthamoeba castellanii strain ATCC 30234 was grown in $75 \mathrm{~cm}^{2}$ culture flasks at $30{ }^{\circ} \mathrm{C}$ for 4 days with $50 \mathrm{~mL}$ of peptone/yeast extract/glucose (PYGC) medium (10 g proteose peptone, $10 \mathrm{~g}$ yeast extract, $10.1 \mathrm{~g}$ glucose, $5 \mathrm{~g} \mathrm{NaCl}, 0.95 \mathrm{~g}$ L-cysteine hydrochloride, $1.74 \mathrm{~g} \mathrm{Na}_{2} \mathrm{HPO}_{4}$, and $1.36 \mathrm{~g}$ $\mathrm{KH}_{2} \mathrm{PO}_{4}$ in 1 liter of distilled water with the $\mathrm{pH}$ adjusted to 6.8). The cells were harvested by centrifugation and re-suspended in PYGC medium to approximately $1 \times 10^{5} / \mathrm{mL}$. The amoebal suspension was distributed into each well of 12 -well micro-plates at $30{ }^{\circ} \mathrm{C}$ until the cells formed monolayers. Just before processing the water samples, the PYGC medium was removed from each well, and the cells were washed twice with $1 \mathrm{ml}$ of Neff's amoebae saline (120 mg NaCl, $3 \mathrm{mg} \mathrm{MgCl}$, $3 \mathrm{mg} \mathrm{CaCl}, 142 \mathrm{mg} \mathrm{Na} 2 \mathrm{HPO}_{4}$, and $136 \mathrm{mg} \mathrm{KH}_{2} \mathrm{PO}_{4}$ in 1 liter of distilled water).

From the $3 \mathrm{~mL}$ processed bath water samples, a $1.1 \mathrm{~mL}$ sample solution was inoculated into the amoebal micro-plate wells (amoebic co-culture). After incubating for 5-7 days at $30{ }^{\circ} \mathrm{C}, 100 \mu \mathrm{L}$ from the amoebic co-cultures were inoculated onto WYO-alpha plates as described above. DNA was isolated from $1 \mathrm{~mL}$ of the amoebic co-culture plates and used for real-time qPCR (68 samples) as described below. When heavy contamination with other bacteria was observed in the culture with amoebic co-culture, DNA extracted from the amoebic co-culture plates, which was stored at $-20{ }^{\circ} \mathrm{C}$, was also used for 16S rRNA gene PCR and sequencing to detect the presence of Legionella in the samples (14 samples).

\subsection{DNA Extraction}

DNA was extracted using the simplified alkaline DNA preparation method previously described [18]. In brief, $1 \mathrm{~mL}$ of a 50-fold concentrated sample was centrifuged at $13,000 \mathrm{~g}$ for $10 \mathrm{~min}$ at $4{ }^{\circ} \mathrm{C}$, and the supernatant was discarded to a volume of $40 \mu \mathrm{L}$. A suspension of the pellet $(40 \mu \mathrm{L})$ was mixed with $50 \mu \mathrm{L}$ of $50 \mathrm{mmol} / \mathrm{L} \mathrm{NaOH}$ by vortexing and then boiled for $15 \mathrm{~min}$. After rapid cooling, the material was neutralized with $8 \mu \mathrm{L}$ of $1 \mathrm{~mol} / \mathrm{L}$ Tris- $\mathrm{HCl}(\mathrm{pH} 7.0)$ and centrifuged at 13,000 $\mathrm{g}$ for $10 \mathrm{~min}$ at $4{ }^{\circ} \mathrm{C}$. The supernatant was stored at $-20^{\circ} \mathrm{C}$ until use.

\subsection{Quantitative Real-Time PCR (Real-Time qPCR)}

Real-time qPCR was performed as previously described using a Cycleave PCR Legionella (5S rRNA) Detection Kit (Takara Bio Co., Shiga, Japan). Genomic DNA extracted from L. pneumophila (ATCC 33152), as described above, was used as the external standard. The number of bacterial cells used for the initial purified DNA solutions were calculated according to the method of Joly et al. [16]. PCR reactions with duplicate standards, positive and negative controls, and samples were performed using an ABI PRISM 7900HT Real-time qPCR System (Applied Biosystems, Foster City, CA, USA) according to the manufacturer's instructions. In brief, reaction mixtures $(25 \mu \mathrm{L})$ contained $12.5 \mu \mathrm{L}$ of $2 \times$ Cycleave Reaction Mixture, $5 \mu \mathrm{L}$ of $5 \mathrm{~S}$ primers/Probe Mix, $2.5 \mu \mathrm{L}$ of $\mathrm{dH}_{2} \mathrm{O}$, and $5 \mu \mathrm{L}$ of each DNA sample. Cycling conditions were an initial incubation at $95{ }^{\circ} \mathrm{C}$ for $10 \mathrm{~s}$, followed by 45 cycles of 
denaturation at $95{ }^{\circ} \mathrm{C}$ for $5 \mathrm{~s}$, annealing at $55^{\circ} \mathrm{C}$ for $10 \mathrm{~s}$, and extension at $72{ }^{\circ} \mathrm{C}$ for $20 \mathrm{~s}$. The number of cells in each sample was automatically calculated by comparing the threshold cycle values to our constructed standard curve using the ABI PRISM 7900HT SDS Software (Applied Biosystems). It was confirmed that amoebic DNA is not amplified by the real-time qPCR (data not shown).

\subsection{S rRNA Gene PCR and Nucleotide Sequencing}

To examine the presence of Legionella in samples that had exhibited bacterial overgrowth $(\mathrm{n}=14)$, a 16S rRNA gene PCR was performed as described previously [18]. PCR product specificity was confirmed by Southern blot hybridization with a 386-mer digoxigenin-labeled Legionella 16S rRNA probe. It was confirmed that amoebic DNA is not amplified by the 16S rRNA gene PCR (data not shown). The PCR products were purified using a QIAamp PCR purification kit (Qiagen K.K., Tokyo, Japan) and directly sequenced in both directions using forward and reverse primers with a BigDye Terminator v1.1 Cycle Sequencing Kit (Applied Biosystems). Homology searches were performed using the BLAST software on the NCBI home page (http://www.ncbi.nlm.nih.gov).

\section{Results}

\subsection{Legionella-Positive Culture Samples}

Using conventional culturing, Legionella were detected in 11 of the 68 samples (16.2\%). The details of these 11 samples are shown in Table 1. L. pneumophila was identified positive in all 11 isolates by the culture method. Among these, serogroups 1 and 5 were predominant. Bacterial numbers ranged from $7.0 \times 10^{2}$ (sample No.\#27 and \#51) to $1.6 \times 10^{5}$ (\# 2) colony-forming units (CFU) /L. In contrast, when using the conventional culture method combined with the amoebic co-culture technique, L. pneumophila was detected in only two of the 68 samples (\#42 and \#51 in Table 1). \#51 had a bacterial load of $2.5 \times 10^{5} \mathrm{CFU} / \mathrm{L}$, and \#42 had too many Legionella colonies to count. We could not evaluate the presence of Legionella in 14 samples because the plates were overgrown with other bacterial species and Legionella colonies could not be identified. To examine the presence of Legionella in the 14 amoebic co-cultured samples, 16S rRNA gene PCR and sequencing were performed using DNA samples from these cultures. Two samples were Legionella-positive, and the remaining 12 samples were Legionella-negative. Therefore, a total of four of 68 samples (5.9\%) were positive in the culture with amoebic co-culture.

Ten of the 11 samples positive by culturing were also positive by real-time qPCR without amoebic co-culture (Table 1). The bacterial numbers ranged from $2.6 \times 10^{4}(\# 25)$ to $1.2 \times 10^{7}$ (\#2) cells $/ \mathrm{L}$ (Table 1). All of the 11 samples positive by culturing were positive by real-time qPCR after amoebic co-culture. The cell numbers ranged from $1.2 \times 10^{5}(\# 25)$ to $1.1 \times 10^{12}(\# 10)$ cells $/ \mathrm{L}$ (Table 1). Using real-time qPCR after amoebic co-culture, more than 10-fold higher bacterial numbers were detected in eight of the 11 Legionella-positive samples (Table 1) compared with the same samples without amoebic co-culture. 
Table 1. Results of the real-time qPCR in the culture-positive 11 bath water samples.

\begin{tabular}{|c|c|c|c|c|}
\hline \multirow[b]{2}{*}{ Sample No. } & \multicolumn{2}{|c|}{ Culture Method } & \multicolumn{2}{|c|}{ Real-Time qPCR Method (Cell/L) } \\
\hline & $\begin{array}{l}\text { Legionella Counts } \\
(\mathrm{CFU} / \mathrm{L})\end{array}$ & $\begin{array}{l}\text { Legionella Species } \\
\left.\text { and Serogroup (SG }{ }^{a}\right)\end{array}$ & $\begin{array}{l}\text { Amoebic } \\
\text { Co-Culture }\end{array}$ & $\begin{array}{c}\text { Without Amoebic } \\
\text { Co-Culture }\end{array}$ \\
\hline 2 & $1.6 \times 10^{5}$ & L. pneumophila SG 3 & $3.1 \times 10^{7}$ & $1.2 \times 10^{7}$ \\
\hline 4 & $1.2 \times 10^{3}$ & L. pneumophila SG 5 & $3.7 \times 10^{8 *}$ & $7.3 \times 10^{4}$ \\
\hline 10 & $1.2 \times 10^{3}$ & L. pneumophila SGs 1, 5 & $1.1 \times 10^{12 *}$ & $\mathrm{ND}^{\mathrm{b}}$ \\
\hline 25 & $1.2 \times 10^{3}$ & L. pneumophila SG 10 & $1.2 \times 10^{5}$ & $2.6 \times 10^{4}$ \\
\hline 27 & $7.0 \times 10^{2}$ & L. pneumophila SG 6 & $3.2 \times 10^{6 *}$ & $1.4 \times 10^{5}$ \\
\hline 32 & $3.0 \times 10^{3}$ & L. pneumophila $\mathrm{NT}^{\mathrm{c}}$ & $6.4 \times 10^{6 *}$ & $4.8 \times 10^{4}$ \\
\hline 41 & $3.8 \times 10^{3}$ & L. pneumophila SG10 & $5.7 \times 10^{9 *}$ & $9.8 \times 10^{5}$ \\
\hline $42 * *$ & $2.7 \times 10^{3}$ & L. pneumophila SGs 1,3 & $8.4 \times 10^{9 *}$ & $2.6 \times 10^{5}$ \\
\hline $51 * *$ & $7.0 \times 10^{2}$ & L. pneumophila SG 5 & $6.1 \times 10^{7 *}$ & $7.2 \times 10^{5}$ \\
\hline 56 & $8.0 \times 10^{3}$ & L. pneumophila SGs 1,5 & $1.6 \times 10^{9 *}$ & $7.3 \times 10^{5}$ \\
\hline 61 & $3.2 \times 10^{3}$ & L. pneumophila SGs 1,5 & $7.0 \times 10^{5}$ & $1.9 \times 10^{5}$ \\
\hline
\end{tabular}

Notes: *: Using real-time qPCR with amoebic co-culture, more than 10 -fold higher bacterial numbers compared with the same samples without amoebic co-culture are observed. ${ }^{* *}:$ L. pneumophila was also detected in the sample by the culture method combined with the amoebic co-culture technique. (a) SG: serogroup; ${ }^{(b)} \mathrm{ND}$ : not detected (less than $10^{2}$ cell/L); ${ }^{(c)} \mathrm{NT}$ : non-typable because of non-aggulutinable against polyclonal antisera to L. pneumophila serogroup 1 to 14 .

\subsection{Legionella-Negative Culture Samples}

Tables 2 and 3 show the results of the 57 samples that were Legionella-negative according to conventional culturing. Of these 57 samples, Legionella was detected in 31 samples by real-time qPCR after culturing both with and without amoebae (Table 2). Using real-time qPCR on samples without amoebic co-culture, the bacterial numbers detected ranged from $1.6 \times 10^{2}(\# 15)$ to $1.4 \times 10^{5}(\# 6)$ cells/L. However, for samples cultured with amoebic co-culture, real-time qPCR detected bacterial numbers ranging from $1.9 \times 10^{2}(\# 69)$ to $3.8 \times 10^{5}(\# 19)$ cells/L (Table 2$)$. In nine of the 31 samples, more than 10-fold higher bacterial numbers were observed compared with the same samples without amoebic co-culture (Table 2).

Table 3 shows the results of the remaining 26 samples that were Legionella-negative by conventional culturing. In these 26 samples, Legionella were detected by real-time qPCR in samples co-cultured either with or without amoeba, but not both, or were not detected at all. There were 15 positive samples by real-time qPCR only after amoebic co-culturing (Table 3 ). The bacterial numbers ranged from $9.1 \times 10^{2}(\# 47)$ to $1.4 \times 10^{9}(\# 46)$ cells /L (Table 3$)$. There were five positive samples by real-time qPCR only without amoebic co-culture (\#17,\#35, \#55,\#68, and \#71). The bacterial numbers ranged from $4.7 \times 10^{2}(\# 35)$ to $3.1 \times 10^{3}(\# 55)$ cells $/ \mathrm{L}$. Using real-time qPCR with amoebic co-culture techniques, more than 10-fold higher bacterial numbers compared with the same samples without amoebic co-culture were observed in 13 of the 26 culture-negative samples (Table 3 ). 
Table 2. Results of the real-time qPCR in the culture-negative 31 bath water samples.

\begin{tabular}{|c|c|c|}
\hline \multirow{2}{*}{ Sample No. } & \multicolumn{2}{|c|}{ Real-Time qPCR Method (Cell/ L) } \\
\hline & Amoebic Co-Culture & Without Amoebic Co-Culture \\
\hline 3 & $5.7 \times 10^{2}$ & $3.5 \times 10^{2}$ \\
\hline 5 & $5.8 \times 10^{3 *}$ & $1.8 \times 10^{2}$ \\
\hline 6 & $2.0 \times 10^{5}$ & $1.4 \times 10^{5}$ \\
\hline 7 & $2.7 \times 10^{3}$ & $3.0 \times 10^{3}$ \\
\hline 15 & $3.8 \times 10^{4 *}$ & $1.6 \times 10^{2}$ \\
\hline 18 & $1.9 \times 10^{3}$ & $2.1 \times 10^{3}$ \\
\hline 19 & $3.8 \times 10^{5}$ & $7.9 \times 10^{4}$ \\
\hline 21 & $3.4 \times 10^{3}$ & $2.5 \times 10^{3}$ \\
\hline 23 & $1.9 \times 10^{3}$ & $3.2 \times 10^{2}$ \\
\hline 24 & $1.0 \times 10^{4}$ & $8.7 \times 10^{3}$ \\
\hline 29 & $7.8 \times 10^{4}$ & $1.5 \times 10^{4}$ \\
\hline 30 & $7.2 \times 10^{2}$ & $4.2 \times 10^{3}$ \\
\hline 33 & $3.8 \times 10^{4 *}$ & $1.0 \times 10^{3}$ \\
\hline 34 & $7.9 \times 10^{2}$ & $1.9 \times 10^{3}$ \\
\hline 36 & $2.7 \times 10^{4 *}$ & $8.0 \times 10^{2}$ \\
\hline 38 & $2.8 \times 10^{4}$ & $7.0 \times 10^{3}$ \\
\hline 39 & $9.9 \times 10^{4 *}$ & $4.6 \times 10^{3}$ \\
\hline 43 & $1.9 \times 10^{4}$ & $3.4 \times 10^{3}$ \\
\hline 44 & $6.1 \times 10^{4}$ & $2.2 \times 10^{4}$ \\
\hline 48 & $4.4 \times 10^{2}$ & $5.2 \times 10^{3}$ \\
\hline 49 & $7.8 \times 10^{3} *$ & $5.7 \times 10^{2}$ \\
\hline 50 & $1.2 \times 10^{3}$ & $1.5 \times 10^{3}$ \\
\hline 52 & $9.1 \times 10^{3} *$ & $4.7 \times 10^{2}$ \\
\hline 53 & $8.8 \times 10^{2}$ & $1.0 \times 10^{4}$ \\
\hline 54 & $1.2 \times 10^{3}$ & $9.7 \times 10^{2}$ \\
\hline 57 & $5.7 \times 10^{3}$ & $2.3 \times 10^{3}$ \\
\hline 59 & $1.8 \times 10^{5}$ & $1.0 \times 10^{5}$ \\
\hline 63 & $1.0 \times 10^{5 *}$ & $1.6 \times 10^{3}$ \\
\hline 64 & $1.1 \times 10^{5 *}$ & $1.3 \times 10^{3}$ \\
\hline 69 & $1.9 \times 10^{2}$ & $4.6 \times 10^{3}$ \\
\hline 70 & $1.4 \times 10^{3}$ & $7.6 \times 10^{3}$ \\
\hline
\end{tabular}

Note: *: Using real-time qPCR with amoebic co-culture, more than 10 -fold higher bacterial numbers compared with the same samples without amoebic co-culture are observed.

Table 3. Results of the real-time qPCR in the culture-negative 26 samples other than the 31 samples shown in Table 2.

\begin{tabular}{ccc}
\hline \multirow{2}{*}{ Sample No. } & \multicolumn{2}{c}{ Real-Time qPCR Method (Cell/L) } \\
\cline { 2 - 3 } & Amoebic Co-Culture & Without Amoebic Co-Culture \\
\hline 11 & $3.4 \times 10^{3 *}$ & ND $^{\text {a }}$ \\
13 & $2.2 \times 10^{4 *}$ & ND \\
14 & $3.6 \times 10^{3 *}$ & ND \\
20 & $1.2 \times 10^{4 *}$ & ND \\
28 & $9.5 \times 10^{2}$ & ND \\
31 & $1.2 \times 10^{4 *}$ & ND \\
\end{tabular}


Table 3. Cont.

\begin{tabular}{ccc}
\hline \multirow{2}{*}{ Sample No. } & \multicolumn{2}{c}{ Real-Time qPCR Method (Cell/L) } \\
\cline { 2 - 3 } & Amoebic Co-Culture & Without Amoebic Co-Culture \\
\hline 37 & $1.0 \times 10^{4 *}$ & ND \\
40 & $5.3 \times 10^{3 *}$ & ND \\
46 & $1.4 \times 10^{9 *}$ & ND \\
47 & $9.1 \times 10^{2}$ & ND \\
58 & $3.7 \times 10^{4 *}$ & ND \\
62 & $1.1 \times 10^{5 *}$ & ND \\
65 & $1.1 \times 10^{5 *}$ & ND \\
66 & $2.3 \times 10^{6 *}$ & ND \\
17 & ND & $2.7 \times 10^{3}$ \\
35 & ND & $4.7 \times 10^{2}$ \\
55 & ND & $3.1 \times 10^{3}$ \\
68 & ND & $2.4 \times 10^{3}$ \\
71 & ND & $7.0 \times 10^{2}$ \\
1 & ND & ND \\
16 & ND & ND \\
22 & ND & ND \\
45 & ND & ND \\
60 & ND & ND \\
67 & ND & ND \\
\hline
\end{tabular}

Notes: *: Using real-time qPCR with amoebic co-culture, more than 10-fold higher bacterial numbers compared with the same samples without amoebic co-culture are observed; ${ }^{\mathrm{a}} \mathrm{ND}$ : not detected (less than $10^{2}$ cells/L).

\subsection{Comparison of Detection Rates between the Culture and Real-Time qPCR Methods with or} without Amoebic Co-Culture Techniques

Table 4 summarizes the comparison of Legionella detection rates between the culture and real-time qPCR methods with or without amoebic co-culture techniques. Positive detection rates of the culture and real-time qPCR methods after with and without amoebic co-culture were $16.2 \%(11 / 68), 83.8 \%$ $(57 / 68)$, and $67.6 \%(46 / 68)$, respectively (Table 4). Of the 57 samples that were negative using the culture method, 46 and 36 samples were positive using real-time qPCR after culturing with and without amoebic co-culture, respectively (Table 4). On the other hand, of the 11 samples that were positive using the culture method, zero and one (10.0\%) were negative using real-time qPCR with and without amoebic co-culture, respectively. Additionally, of the 21 samples that were negative using real-time qPCR without amoebic co-culture, 10 (48\%) were positive when using real-time qPCR after amoebic co-culture. As shown in Table 5, there was a significant difference (chi square $=4.84$; $p=0.0278$ ) in detection of Legionella between real-time qPCR methods with and without the amoebic co-culture techniques. 
Table 4. Comparison between the culture and real-time qPCR methods with or without amoebic co-culture techniques.

\begin{tabular}{|c|c|c|c|c|c|c|}
\hline \multirow{3}{*}{ Method } & \multirow{3}{*}{ Detection } & \multicolumn{4}{|c|}{ Real-Time qPCR Method } & \multirow{3}{*}{ Total } \\
\hline & & \multicolumn{2}{|c|}{ With Amoebic Co-Culture } & \multicolumn{2}{|c|}{ Without Amoebic Co-Culture } & \\
\hline & & Positive & Negative & Positive & Negative & \\
\hline \multirow{2}{*}{ Culture method } & positive & 11 & 0 & 10 & 1 & 11 \\
\hline & negative & 46 & 11 & 36 & 21 & 57 \\
\hline Total & & 57 & 11 & 46 & 22 & 68 \\
\hline
\end{tabular}

Table 5. Relation between amoebic co-culture technique and real-time qPCR method for detection of Legionella in bath water samples.

\begin{tabular}{cccc}
\hline \multirow{2}{*}{ Method } & \multicolumn{2}{c}{ Real-Time qPCR } & \multirow{2}{*}{ Total } \\
\cline { 2 - 3 } & Positive & Negative & \\
\hline With amoebic co-culture & 57 & 11 & 68 \\
Without amoebic co-culture & 46 & 22 & 68 \\
Total & 99 & 33 & 136 \\
\hline
\end{tabular}

Note: Amoebic co-culture technique prior to real-time qPCR results in more sensitive detection of Legionella $($ Chi square $=4.84, p<0.05)$.

\section{Discussion}

In this study, we applied the amoebic co-culture technique to the detection of Legionella from bath water samples, the most common source of legionellosis in Japan. To the best of our knowledge, this is the first report to evaluate the efficacy of the amoebic co-culture technique for detecting Legionella from bath water. Co-culturing bath water samples with amoeba did not increase the detection rate of Legionella, suggesting that this technique might not be effective for Legionella detection in bath water samples. However, improvements to the culture method with amoebic co-culture, such as heating and/or acid treatments for amoebic co-cultured samples and/or shortening the incubation periods with amoeba (3-4 days), may result in more accurate detection of Legionella in bath water samples. Further studies are required to test these conditions.

The application of the amoebic co-culture technique to real-time qPCR detection of Legionella from bath water samples increased the bacterial numbers detected and the detection rate of Legionella compared with the method without the amoebic co-culture. Real-time qPCR is known to be a much more sensitive method for detecting Legionella in environmental water samples compared with the culture method. In previous studies, real-time qPCR was reported to be 1.8-4.0 times more sensitive than the culture method for detecting Legionella from water samples collected from a hot water system, a spa, and a cooling tower [15,16,23]. Similarly in our study, real-time qPCR was 4.4 times (44/10 in Table 4) more sensitive than the culture method for detecting Legionella from bath water. Furthermore, the amoebic co-culture technique increased the sensitivity of the real-time qPCR and approximately $15(71.4 \%)$ of the 21 previously negative samples tested positive after amoebic co-culture. Our results indicate that application of the amoebic co-culture technique prior to real-time qPCR is more effective for the sensitive detection of Legionella from bath water samples. 
L. pneumophila survives within amoebae by a mechanism similar to one that enables it to survive within macrophages [24,25]. Once taken into amoebae by coiling phagocytosis, L. pneumophila escapes the fusion of the phagosome and lysosome and replicates within the amoebae [26]. This ability to invade and multiply within host cells is considered to correlate with its pathogenicity [27]. Segal and Shuman (1999) reported that L. pneumophila uses the same genes to multiply within A. castellanii and human macrophages [28]. In addition, Cirillo et al. (1999) demonstrated that intracellular growth in A. castellanii affects monocyte entry mechanisms and enhances the virulence of L. pneumophila [29]. Therefore, positive real-time qPCR signals following amoebic co-culture may indicate the existence of viable and virulent Legionella in samples [30]. Since real-time qPCR cannot differentiate viable and virulent from non-virulent Legionella, the application of an amoebic co-culture technique to real-time qPCR may be useful to detect these virulent Legionella. In this study, more than 10-fold higher bacterial numbers were observed by real-time qPCR with the co-culture technique in 30 samples $(30 / 68,44.1 \%)$ compared with the same samples without co-culturing (Tables 1 to 3$)$. This suggests that viable and virulent Legionella might be detected. However, higher bacterial numbers were not observed after propagation by amoebae in the remaining 32 samples (excluding six samples, \#1, \#16, \#22, \#45, \#60, and \#67 in Table 3), suggesting that non-virulent and/or non-viable Legionella or just DNA might have been detected.

Using the culture method, we detected Legionella in $16.2 \%(11 / 68)$ of bath water samples. This result was relatively lower than the Legionella detected by Sasahara et al. (2004) (49.5\%, 52/105), Suzuki et al. (2002) (48.0\%, 471/981), Karasudani et al. (2009) (39.4\%, 78/198), and Furuhata et al. (2004) $(28.7 \%, 204 / 710)$ in Japanese hot springs [7-10], and by Lin et al. (2007) in Taiwanese hot springs $(21.0 \%, 4 / 19)$ [11]. Bath water contaminated with L. pneumophila is the main source of legionellosis in Japan. Therefore, surveillance for Legionella, particularly L. pneumophila, is crucial for legionellosis control. In our study, Legionella identified by the culture were L. pneumophila SG1, SG3, SG5, SG6, SG10, and NA. Among these L. pneumophila, SG1, SG5, and SG6 were the most common serogroups detected from Japanese hot springs and L. pneumophila SG1 or SG5 was the causative agent of three large legionellosis outbreaks in Japan [3-5]. Thus, routine surveillance for Legionella contamination of bath water is essential for preventing legionellosis outbreaks

\section{Conclusions}

The application of the amoebic co-culture technique prior to real-time qPCR was useful for the sensitive detection of Legionella from bath water samples. Furthermore, the combination of amoebic co-culture and real-time qPCR might be a useful method to detect viable and virulent Legionella because the ability to invade and multiply within FLA is considered to correlate with their pathogenicity for humans.

\section{Acknowledgments}

The authors gratefully acknowledge Drs Y. Suzuki and C. Nakajima of the Hokkaido University Research Center for Zoonosis Control for their helpful discussions. This work was supported by grants to AE (GK24590841) and HM (GK25460538) from the Japan Society for the Promotion of Science. 


\section{Author Contributions}

Akiko Edagawa, Akio Kimura, and Hiroshi Miyamoto conceived the study. Akiko Edagawa and Akio Kimura performed and designed the experiments and analyzed the data. Takako Kawabuchi-Kurata helped with DNA sequencing of PCR products. Katsunori Furuhata and Shinichi Adachi helped with research design and provided samples. Akio Kimura and Akiko Edagawa wrote the first draft of the manuscript, Hiroshi Miyamoto supervised the whole study. All authors read and approved the final manuscript.

\section{Conflicts of Interest}

The authors declare no conflict of interest.

\section{References}

1. Fields, B.S.; Benson, R.F.; Besser, R.E. Legionella and Legionnaires' disease: 25 Years of investigation. Clin. Microbiol. Rev. 2002, 15, 506-526.

2. Pagnier, I.; Raoult, D.; la Scola, B. Isolation and identification of amoeba-resisting bacteria from water in human environment by using an Acanthamoeba polyphaga co-culture procedure. Environ. Microbiol. 2008, 10, 1135-1144.

3. Okada, M.; Kawano, K.; Kura, F.; Amemura-Maekawa, J.; Watanabe, H.; Yagita, K.; Endo, T.; Suzuki, S. The largest outbreak of legionellosis in Japan associated with spa baths: Epidemic curve and environmental investigation. Kansenshogaku Zasshi 2005, 79, 365-374.

4. Nakamura, H.; Yagyu, H.; Kishi, K.; Tsuchida, F.; Oh-Ishi, S.; Yamaguchi, K.; Matsuoka, T.A. Large outbreak of Legionnaires' disease due to an inadequate circulating and filtration system for bath water-epidemiologic manifestations. Intern. Med. 2003, 42, 806-811.

5. Kura, F.; Amemura-Maekawa, J.; Yagita, K.; Endo, T.; Ikeno, M.; Tsuji, H.; Taguchi, M.; Kobayashi, K.; Ishii, E.; Watanabe, H. Outbreak of Legionnaires' disease on a cruise ship linked to spa-bath filter stones contaminated with Legionella pneumophila serogroup 5. Epidemiol. Infect. 2006, 134, 385-391.

6. Kuroki, T.; Ishihara, T.; Ito, K.; Kura, F. Bathwater-associated cases of legionellosis in Japan, with a special focus on Legionella concentrations in water. Jpn. J. Infect. Dis. 2009, 62, 201-205.

7. Sasahara, T.; Kikuno, R.; Okuda, S.; Sekiguchi, T.; Satoh, Y.; Takayama, Y.; Aoki, M.; Inoue, M. Physicochemical factors influencing distribution of Legionella species in Japanese hot springs. Kansenshogaku Zasshi 2004, 78, 545-553.

8. Suzuki, A.; Ichinose, M.; Matsue, T.; Amano, Y.; Terayama, T.; Izumiyama, S.; Endo, T. Occurrence of Legionella bacteria in a variety of environmental waters-From April, 1996 to November, 2000. Kansenshogaku Zasshi 2002, 76, 703-710.

9. Karasudani, T.; Kuroki, T.; Otani, K.; Yamaguchi, S.; Sasaki, M.; Saito, S.; Fujita, M.; Sugiyama, K.; Nakajima, H.; Murakami, K.; et al. Legionella contamination risk factors in non-circulating hot spring water. Kansenshogaku Zasshi 2009, 83, 36-44.

10. Furuhata, K.; Hara, M.; Yoshida, S.; Fukuyama, M. Distribution of Legionella spp. in hot spring baths in Japan. Kansenshogaku Zasshi 2004, 78, 710-716. 
11. Lin, Y.E.; Lu, W.; Huang, H.I.; Huang, W.K. Environmental survey of Legionella pneumophila in hot springs in Taiwan. J. Toxicol. Environ. Health.. 2007, 70, 84-87.

12. García, M.T.; Jones, S.; Pelaz, C.; Millar, R.D.; Kwaik, Y.A. Acanthamoeba polyphaga resuscitates viable non-culturable Legionella pneumophila after disinfection. Environ. Microbiol. 2007, 9, 1267-1277.

13. Alleron, L.; Merlet, N.; Lacombe, C.; Frere, J. Long-term survival of Legionella pneumophila in the viable but nonculturable state after monochloramine treatment. Curr. Microbiol. 2008, 57, 497-502.

14. Hussong, D.; Colwell, R.R.; O’brien, M.O.; Welss, E.; Pearson, R.; Wiener, R.M.; Burge, W.D.J.S. Viable Legionella pneumophila not detectable by culture on agar media. Nat. Biotechnol. 1987, 5, 947-950.

15. Bonetta, S.; Bonetta, S.; Ferretti, E.; Balocco, F.; Carraro, E. Evaluation of Legionella pneumophila contamination in Italian hotel water systems by quantitative real-time PCR and culture methods. J. Appl. Microbiol. 2010, 108, 1576-1583.

16. Joly, P.; Falconnet, P.A.; Andre, J.; Weill, N.; Reyrolle, M.; Vandenesch, F.; Maurin, M.; Etienne, J.; Jarraud, S. Quantitative real-time Legionella PCR for environmental water samples: Data interpretation. Appl. Environ. Microbiol. 2006, 72, 2801-2808.

17. Touron-Bodilis, A.; Pougnard, C.; Frenkiel-Lebosse, H.; Hallier-Soulier, S. Usefulness of real-time PCR as a complementary tool to the monitoring of Legionella spp. and Legionella pneumophila by culture in industrial cooling systems. J. Appl. Microbiol. 2011, 111, 499-510.

18. Edagawa, A.; Kimura, A.; Doi, H.; Tanaka, H.; Tomioka, K.; Sakabe, K.; Nakajima, C.; Suzuki, Y. Detection of culturable and nonculturable Legionella species from hot water systems of public buildings in Japan. J. Appl. Microbiol. 2008, 105, 2104-2114.

19. Dusserre, E.; Ginevra, C.; Hallier-Soulier, S.; Vandenesch, F.; Festoc, G.; Etienne, J.; Jarraud, S.; Molmeret, M. A PCR-based method for monitoring Legionella pneumophila in water samples detects viable but noncultivable legionellae that can recover their cultivability. Appl. Environ. Microbiol. 2008, 74, 4817-4824.

20. La Scola, B.; Mezi, L.; Weiller, P.J.; Raoult, D. Isolation of Legionella anisa using an amoebic coculture procedure. J. Clin. Microbiol. 2001, 39, 365-366.

21. Rowbotham, T.J. Isolation of Legionella pneumophila serogroup 1 from human feces with use of amebic cocultures. Clin. Infect. Dis. 1998, 26, 502-503.

22. Schalk, J.A.; van Leeuwen, A.E.D.; Lodder, W.J.; de Man, H.; Euser, S.; den Boer, J.W.; de Roda Husman, A.M. Isolation of Legionella pneumophila from pluvial floods by amoebal coculture. Appl. Environ. Microbiol. 2012, 78, 4519-4521.

23. Guillemet, T.A.; Levesque, B.; Gauvin, D.; Brousseau, N.; Giroux, J.P.; Cantin, P. Assessment of real-time PCR for quantification of Legionella spp. in spa water. Lett. Appl. Microbiol. 2010, 51, 639-644.

24. Horwitz, M.A. Characterization of avirulent mutant Legionella pneumophila that survive but do not multiply within human monocytes. J. Exp. Med. 1987, 166, 1310-1328.

25. Miyamoto, H.; Yoshida, S.; Taniguchi, H.; Shuman, H.A. Virulence Conversion of Legionella pneumophila by Conjugal Transfer of Chromosomal DNA. J. Bacteriol. 2003, 185, 6712-6718. 
26. Greub, G.; Raoult, D. Microorganisms resistant to free-living amoebae. Clin. Microbiol. Rev. 2004, 17, 413-433.

27. Neumeister, B.; Schoniger, S.; Faigle, M.; Eichner, M.; Dietz, K. Multiplication of different Legionella species in Mono Mac 6 cells and in Acanthamoeba castellanii. Appl. Environ. Microbiol. 1997, 63, 1219-1224.

28. Segal, G.; Shuman, H.A. Legionella pneumophila utilizes the same genes to multiply within Acanthamoeba castellanii and human macrophages. Infect. Immun. 1999, 67, 2117-2124.

29. Cirillo, J.D.; Cirillo, S.L.G.; Yan, L.; Bermudez, L.E.; Falkow, S.; Tompkins, L.S. Intracellular growth in Acanthamoeba castellanii affects monocyte entry mechanisms and enhances virulence of Legionella pneumophila. Infect. Immun. 1999, 67, 4427-4434.

30. Samrakandi, M.M.; Cirillo, S.L.; Ridenour, D.A.; Bermudez, L.E.; Cirillo, J.D. Genetic and phenotypic differences between Legionella pneumophila strains. J. Clin. Microbiol. 2002, 40, $1352-1362$.

(C) 2015 by the authors; licensee MDPI, Basel, Switzerland. This article is an open access article distributed under the terms and conditions of the Creative Commons Attribution license (http://creativecommons.org/licenses/by/4.0/). 